\title{
Wax ester composition of the dominant calanoid copepods of the Greenland Sea/Fram Strait region*
}

\author{
GERHARD KATTNER and MARTIN GRAEVE
}

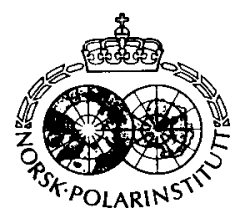

Kattner, G. \& Graeve, M. 1991: Wax ester composition of the dominant calanoid copepods of the Greenland Sea/Fram Strait region. Pp. 479-485 in Sakshaug, E., Hopkins, C. C. E. \& Øritsland, N. A. (eds.): Proceedings of the Pro Mare Symposium on Polar Marine Ecology, Trondheim, 12-16 May 1990. Polar Research 10(2).

The composition of the intact wax esters of Calanus hyperboreus, $C$. finmarchicus, and $C$. glacialis from the Fram Strait area of the Greenland Sea was studied. In addition the fatty acid and alcohol composition of the wax esters was analysed. All copepods were rich in wax esters, especially $C$. hyperboreus in which long-chain wax esters were generally more abundant than in the other species.

The wax ester composition was species dependent but strongly overlapped by spatial variabilities. Because phytoplankton fatty acids were partially incorporated directly into wax esters, the composition of the wax esters was widely influenced by the phytoplankton community which itself varied considerably in the Fram Strait region. Thus, the wax esters of the polar species, collected in the North East Water Polynya near Greenland, were dominated by diunsaturated compounds in the range from $C_{32}$ to $C_{44}$. The shorter chain components resulted from a combination of palmitoleic acid which is typical of diatom lipids with long-chain alcohols. In the marginal ice zone, higher levels of polyunsaturated wax esters were detected due to the presence of the 18:4 fatty acid, typical of a summer phytoplankton population.

Gerhard Kattner and Martin Graeve, Alfred-Wegener-Institut für Polar- und Meeresforschung, Sektion Chemie, Am Handelshafen 12, D-2850 Bremerhaven, Germany.

\section{Introduction}

The herbivorous copepods are an important group in the plankton community of the Greenland Sea (Smith 1988). Their life in high latitudes is dependent upon the seasonal availability of food and on the storage of lipids.

The high lipid content of copepods in Polar regions is mostly a result of an increase in wax esters, which partially account for more than $90 \%$ of the total lipid (Lee 1974, 1975; Sargent et al. 1981; Tande \& Henderson 1988; Kattner et al. 1989). This lipid store enables copepods to survive long periods of food shortage or even periods lacking food; it also enables them to preserve energy for reproduction.

Wax esters are molecules in which a long-chain fatty acid is esterified with a long-chain fatty alcohol. The alcohols are biosynthesised de novo by calanoid copepods (e.g. Sargent et al. 1976), whereas the fatty acids partly reflect their phytoplanktonic dietary input. The principal alcohols are 20:1 and 22:1 with smaller amounts of $16: 0$; the fatty acids are much more variable in composition.

Until now, methods of determining intact wax

* Contribution No. 315 of the Alfred Wegener Institute for Polar and Marine Research esters have provided only an inadequate separation (Lee et al. 1971, 1974; Boon \& de Leeuw 1979; Wakeham \& Frew 1982; Itabashi \& Takagi 1984). In the present study the compositions of intact wax esters of Calanus hyperboreus, $C$. finmarchicus and $C$. glacialis are presented. The results are based on a recent method which allows the separation of wax esters according to their degree of unsaturation (Kattner et al. 1990). With this method it is possible to study, for example, the influence of species variabilities and diet on the wax esters by the examination of intact molecules.

\section{Material and methods}

The calanoid copepods Calanus hyperboreus, $C$. finmarchicus, and C. glacialis were caught in the Fram Strait area between Greenland and Spitsbergen during the 1984 MIZEX cruises of the $R / V$ POLARSTERN and $R / \mathrm{V}$ VALDIVIA. The different species collected at the various stations are indicated in Fig. 1. The copepods were collected by vertical hauls from the upper $100 \mathrm{~m}$ with a bongo net ( 300 and $500 \mu \mathrm{m}$ mesh). Immediately after sampling, individuals were sorted into species and stages, transferred into glass tubes containing 


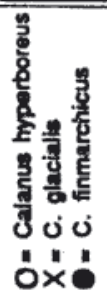

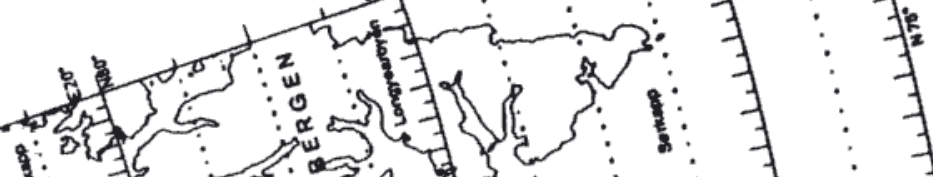

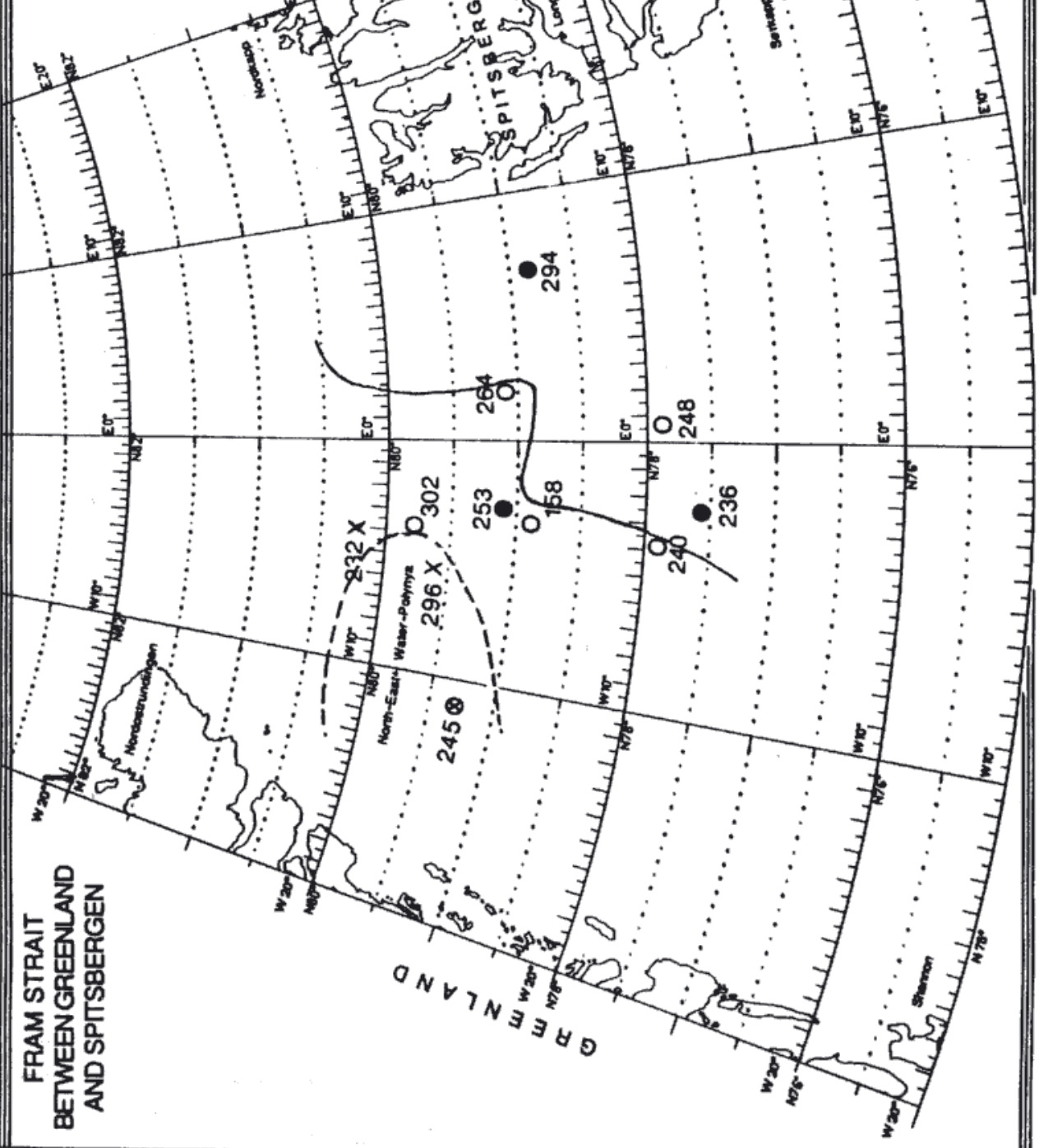


chloroform:methanol $(2: 1 \mathrm{v} / \mathrm{v})$ and stored at $-20^{\circ} \mathrm{C}$ until analysis.

The copepods were homogenised in the storage solution using a Potter homogeniser (Braun, Melsungen, Germany). From an aliquot of the lipid extract, wax esters were separated by thin-layer chromatography on silica gel 60 with hexane:diethylether:acetic acid $(90: 10: 1)$. The bands were scraped off after visualising with $0.1 \%$ dichlorofluorescein in methanol, eluted in chloroform, evaporated to dryness, and redissolved in hexane.

Analyses of the intact wax esters were carried out in a gas chromatograph (Model 5370 Mega Series, Carlo Erba Instruments, Milano, Italy) on a $25 \mathrm{~m} \times 0.25 \mathrm{~mm}$ i.d. wall-coated open tubular bonded, fused silica column coated with a $0.10 \mu \mathrm{m}$ film of a Triglyceride Analysis Phase (TAP, Chrompak, Mühlheim, FRG) using on column injection and temperature programming. The details of the method are described elsewhere by Kattner et al. (1990). The fatty acids and alcohols were analysed according to the method of Kattner \& Fricke (1986).

\section{Results}

The total lipids of all the copepods studied were rich in wax esters (Fig. 2). Calanus hyperboreus had the highest proportion of wax esters in total lipids, with the proportion increasing from the copepoid Stage IV to females. In C. finmarchicus

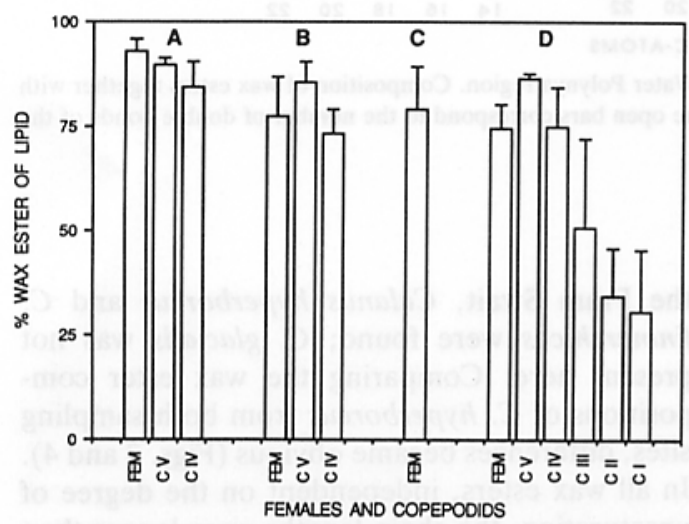

Fig. 2. Percentage of wax ester of total lipid in copepodid stages and females. Comparison of Calanus hyperboreus (A), C. finmarchicus (B), and C. glacialis females (C) from the Arctic, and $C$. finmarchicus (D) from the North Sea. the proportion was less in all stages than in $C$. hyperboreus. The variability was higher in $C$. finmarchicus and the females contained less wax esters than the copepodid Stage V. Generally the wax ester content decreased from adults to the young copepodid stages as reported for $C$. finmarchicus from the North Sea (Fig. 2). The wax ester content of $C$. finmarchicus was similar in both areas. $C$. glacialis females, collected in the Polynya contained about $73 \%$ of wax esters in total lipid, but under the pack ice, levels of more than $90 \%$ were detected.

The wax ester compositions, together with the composition of their fatty acid and alcohol moieties, of the three calanoid copepod species are presented in Figs. 3 and 4. The wax esters were different within the species and varied moreover due to the different sampling locations. Their chain length range was from $\mathrm{C}_{30}$ to $\mathrm{C}_{44}$. Saturated compounds were generally not detected, although their existence might be possible since saturated fatty acids and fatty alcohols were found after wax ester hydrolysis (Figs. 3 and 4).

\section{North East Water Polynya}

In the cold water of the East Greenland Current, Calanus hyperboreus and $C$. glacialis were collected, being typical species for this region. Sampling was carried out in or near the North East Water Polynya at Station 245. As shown in Fig. 3, diunsaturated wax esters accounted for the major portion of the wax ester composition of these two species. In both species the $36: 2$ (number of carbon-atoms:number of double bonds) and 38:2 wax esters were dominant as a combination of the $16: 1$ acid and the $20: 1$ or $22: 1$ alcohols. The other diunsaturated wax esters with chain length of 40-44 C-atoms are most likely combinations of the $20: 1$ and $22: 1$ acids with their corresponding alcohols.

In $C$. glacialis the wax esters with shorter chain length were more abundant than in $C$. hyperboreus. Also monounsaturated wax esters accounted for higher levels in $C$. glacialis in which the major chain length was $36 \mathrm{C}$-atoms. The different composition may result from different possible combinations of fatty acids and alcohols in wax esters. The relatively high proportion of the $14: 0$ acid, in contrast to $C$. hyperboreus, may contribute to this pattern (Fig. 3).

The polyunsaturated wax esters were generally low in both copepods in the Polynya region. Only 


\section{C. hyperboreus}
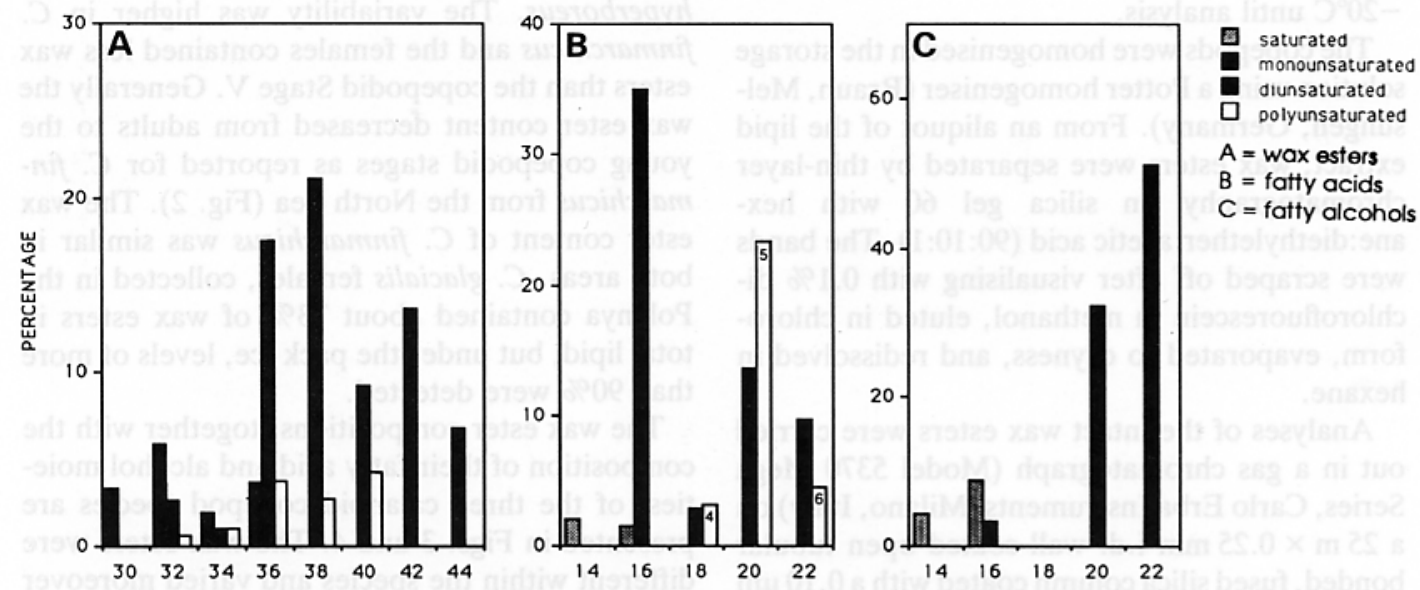

$A=$ wax esters

$B=$ fatty acids

$\mathrm{C}=$ fatty alcohols

CHAIN LENOIH IN C-ATOMS

\section{C. glacialis}
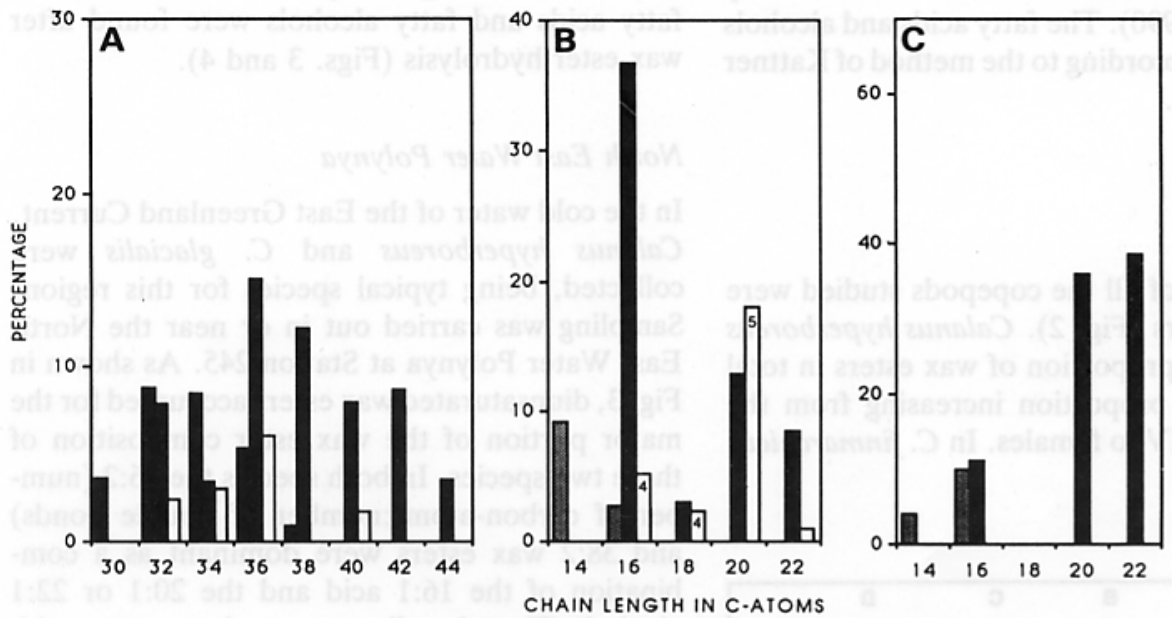

Fig. 3. Calanus hyperboreus and C. glacialis from the North East Water Polynya region. Composition of wax esters together with their fatty acid and alcohol moieties at Station 245. Numbers in the open bars correspond to the number of double bonds of the main polyunsaturated component.

the 20:5 acid accounted for higher levels in the wax esters which results in a small proportion of wax esters with 5 to 6 double bonds. Also the chain lengths of the polyunsaturated wax esters of Calanus glacialis were shorter than those of $C$. hyperboreus.

\section{Marginal ice zone}

Further west in the marginal ice zone (MIZ) of the Fram Strait, Calanus hyperboreus and $C$. finmarchicus were found; $C$. glacialis was not present here. Comparing the wax ester compositions of $C$. hyperboreus from both sampling sites, differences became obvious (Figs. 3 and 4). In all wax esters, independent on the degree of unsaturation, the chain lengths were longer than in the Polynya region. The sum of diunsaturated wax esters was similar despite the change to longer chain lengths. About half of the total wax esters 

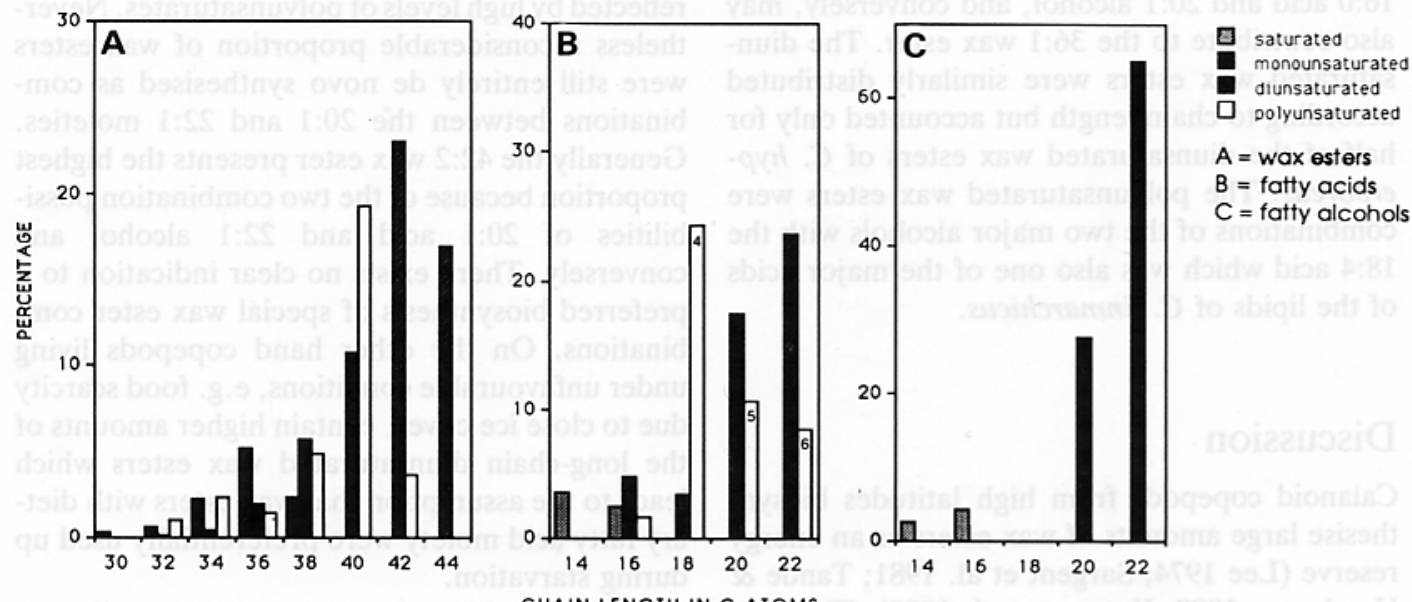

CHAIN LENGIH IN C.ATOMS

\section{C. finmarchicus}
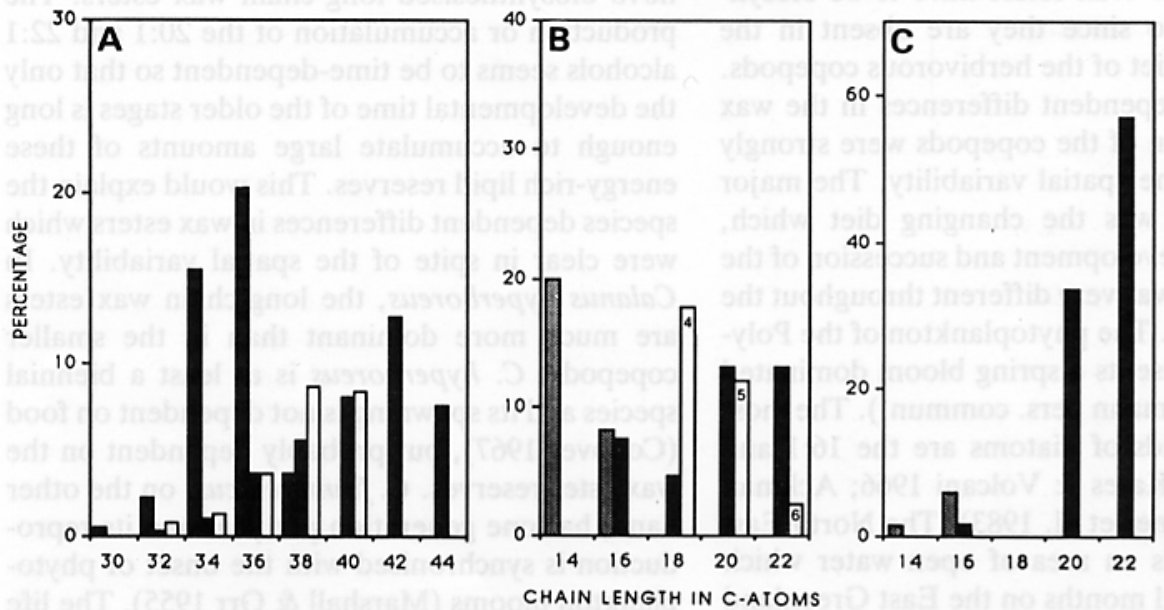

Fig. 4. Calanus hyperboreus and C. finmarchicus from the marginal ice zone. Composition of wax esters together with their fatty acid and alcohol moieties. Numbers in the open bars correspond to the number of double bonds of the main polyunsaturated component.

are combinations of the $20: 1$ and $22: 1$ acids with their corresponding alcohols, which is much more than in the Polynya.

The proportion of monounsaturated wax esters was also low, but the polyunsaturated were much more abundant. This results from a dramatic change in the fatty acids, being now dominated by the 18:4 acid. The 18:4 acid accounted for about $20 \%$ of total wax ester fatty acids. The combination of this acid with the $22: 1$ alcohol was the dominant contributor to the polyunsaturated wax esters of $C$. hyperboreus from this region (Fig. 4).

Comparison of the wax ester compositions of Calanus hyperboreus and C. finmarchicus from the same region (the MIZ) resulted in widely different compositions (Fig. 4). C. finmarchicus was dominated by the $34: 1$ and $36: 1$ wax esters. Due to high amounts of the 14:0 acid, the combination again with the $20: 1$ or $22: 1$ alcohol was 
the major contributor; but the combination of 16:0 acid and 20:1 alcohol, and conversely, may also contribute to the $36: 1$ wax ester. The diunsaturated wax esters were similarly distributed according to chain length but accounted only for half of the diunsaturated wax esters of $C$. hyperboreus. The polyunsaturated wax esters were combinations of the two major alcohols with the 18:4 acid which was also one of the major acids of the lipids of $C$. finmarchicus.

\section{Discussion}

Calanoid copepods from high latitudes biosynthesise large amounts of wax esters as an energy reserve (Lee 1974; Sargent et al. 1981; Tande \& Henderson 1988; Kattner et al. 1989). They are therefore able to survive the long periods of food scarcity in Polar regions and to preserve energy for reproduction. Wax esters have to be biosynthesised de novo since they are absent in the phytoplankton diet of the herbivorous copepods.

The species dependent differences in the wax ester composition of the copepods were strongly overlapped by the spatial variability. The major reason for this was the changing diet which, because of the development and succession of the phytoplankton, was very different throughout the Fram Strait area. The phytoplankton of the Polynya region represents a spring bloom dominated by diatoms (Baumann pers. commun.). The most striking fatty acids of diatoms are the $16: 1$ and 20:5 acids (e.g. Kates \& Volcani 1966; Ackman et al. 1968; Kattner et al. 1983). The North East Water Polynya is an area of open water which occurs for several months on the East Greenland Shelf. It starts opening in the spring and reaches its maximum extension in August. The highest phytoplankton biomass and primary production were found in this region. Fig. 1 describes the Polynya area between 30 June and 4 July 1984. The phytoplankton community of the marginal ice zone represents a summer population, dominated by Phaeocystis $s p$. and dinoflagellates (Smith et al. 1987). Their "marker" fatty acid, especially of Phaeocystis sp., is the 18:4 acid (Harrington et al. 1970; Sargent et al. 1985). Both fatty acids marked considerably the wax ester composition of the copepod species. Thus in the Polynya about half of the diunsaturated wax esters were short-chain esters due to the combination with the $16: 1$ acid. In the MIZ the transfer of the dietary 18:4 acid into the wax ester fraction was reflected by high levels of polyunsaturates. Nevertheless a considerable proportion of wax esters were still entirely de novo synthesised as combinations between the 20:1 and 22:1 moieties. Generally the $42: 2$ wax ester presents the highest proportion because of the two combination possibilities of 20:1 acid and 22:1 alcohol and conversely. There exists no clear indication to a preferred biosynthesis of special wax ester combinations. On the other hand copepods living under unfavourable conditions, e.g. food scarcity due to close ice cover, contain higher amounts of the long-chain diunsaturated wax esters which leads to the assumption that wax esters with dietary fatty acid moiety were preferentially used up during starvation.

Generally the wax ester proportion of total lipids increases in the copepodid stages (Kattner \& Krause 1987), parallel with the amount of de novo biosynthesised long-chain wax esters. The production or accumulation of the $20: 1$ and $22: 1$ alcohols seems to be time-dependent so that only the developmental time of the older stages is long enough to accumulate large amounts of these energy-rich lipid reserves. This would explain the species dependent differences in wax esters which were clear in spite of the spatial variability. In Calanus hyperboreus, the long-chain wax esters are much more dominant than in the smaller copepods. C. hyperboreus is at least a biennial species and its spawning is not dependent on food (Conover 1967), but probably dependent on the wax ester reserves. C. finmarchicus, on the other hand, has one generation per year and its reproduction is synchronised with the onset of phytoplankton blooms (Marshall \& Orr 1955). The life cycle of C. glacialis, annual or biennial, is still in discussion (Tande \& Henderson 1988), but it seems to be somewhat between the other two species, which is also reflected in its wax ester composition.

\section{References}

Ackman, R. G., Tocher, C. S. \& McLachlan, J. 1968: Marine phytoplankter fatty acids. J. Fish. Res. Bd. Can. 25, 16031620.

Boon, J. J. \& de Leeuw, J. W. 1979: The analysis of wax esters, very long mid-chain ketones and sterol ethers isolated from Walvis Bay diatomaceous ooze. Mar. Chem. 7, 117-132.

Conover, R. J. 1967: Reproductive cycle, early development, and fecundity in laboratory populations of the copepod $\mathrm{Cal}$ anus hyperboreus. Crustaceana 13, 61-172. 
Harrington, G. W., Beach, D. H., Dunham, J. E. \& Holz, G. G., Jr. 1970: The polyunsaturated fatty acids of marine dinoflagellates. J. Protozool. 17, 213-219.

Itabashi, Y.\& Takagi, T. 1984: Gas chromatographic resolution on polar open-tubular columns of saturated and unsaturated wax ester isomers differing in combinations of acyl and alcoholic groups. $J$. Chromatogr. 299, 351-363.

Kates, K. \& Volcani, B. E. 1966: Lipid components of diatoms. Biochem. Biophys. Acta 116, 264-278.

Kattner, G. \& Fricke, H. S. G. 1986: Simple gas-liquid chromatographic method for the simultaneous determination of fatty acids and alcohols in wax esters of marine organisms. $J$. Chromatogr. 362, 263-268.

Kattner, G. \& Krause, M. 1987: Changes in lipids during the development of Calanus finmarchicus s.l. from Copepodid I to adult. Mar. Biol. 96, 511-518.

Kattner, G., Gercken, G. \& Eberlein, K. 1983: Development of lipids during a spring plankton bloom in the northern North Sea. I. Particulate fatty acids. Mar. Chem. 14, 149162.

Kattner, G., Graeve, M. \& Ernst, W. 1990: Gas-liquid chromatographic method for the determination of marine wax esters according to the degree of unsaturation. J. Chromatogr. $513,327-332$.

Kattner, G., Hirche, H. J. \& Krause, M. 1989: Spatial variability in lipid composition of calanoid copepods from Fram Strait, the Arctic. Mar. Biol. 102, 473-480.

Lee, R. F. 1974: Lipid composition of the copepod Calanus hyperboreus from the Arctic Ocean. Changes with depth and season. Mar. Biol. 26, 313-318.

Lee, R. F. 1975: Lipids of Arctic zooplankton. Comp. Biochem. Physiol. 51B, 263-266.
Lee, R. F., Nevenzel, J. C. \& Lewis, A. G. 1974: Lipid changes during life cycle of the marine copepod, Euchaeta japonica Marukawa. Lipids 9, 891-898.

Lee, R. F., Nevenzel. J. C. \& Paffenhöfer, G.-A. 1971: The importance of wax esters and other lipids in the marine food chain: phytoplankton and copepods. Mar. Biol. 9, 99-108.

Marshall, S. M. \& Orr, A. P. 1955: The biology of a marine copepod Calanus finmarchicus Gunnerus. Oliver \& Boyd, Edinburgh.

Sargent, J. R., Lee, R. F. \& Nevenzel, J. C. 1976: Marine waxes. Pp. 50-91 in Kolattukudy, P. E. (ed.): Chemistry and biochemistry of natural waxes. Elsevier, Amsterdam.

Sargent, J. R., Gatten, R. R. \& Henderson, R. J. 1981: Lipid biochemistry of zooplankton from high latitudes. Oceanus 7 , 623-632.

Sargent, J. R., Eilertsen, H. C., Falk-Petersen, S. \& Taasen, J. P. 1985: Carbon assimilation and lipid production in phy toplankton in northern Norwegian fjords. Mar. Biol. 85, 109 116.

Smith, S. L. 1988: Copepods in Fram Strait in summer: Distribution, feeding and metabolism. J. Mar. Res. 46, 145-181.

Smith, W. O., Baumann, M. E. M., Wilson, D. L. \& Aletsee, L. 1987: Phytoplankton biomass and productivity in the marginal ice zone of the Fram Strait during summer, 1984. J. Geophys. Res. 92, 6777-6786.

Tande, K. S. \& Henderson, R. J. 1988: Lipid composition of copepodite stages and adult females of Calanus glacialis in Arctic waters of the Barents Sea. Polar Biol. 8, 333-339.

Wakcham, S. G. \& Frew, N. M. 1982: Glass capillary gas chromatography-mass spectrometry of wax esters, steryl esters and triacylglycerols. Lipids 17, 831-843. 